\title{
Simulação humana digital na concepção de postos de trabalho: estudo comparativo de casos
}

\section{Digital human simulation for ergonomic workplace design: comparative study of cases}

\author{
Daniel Braatz ${ }^{1}$ \\ Nilton Luiz Menegon \\ Andréa Regina Martins Fontes ${ }^{1}$ \\ Luiz Antonio Tonin ${ }^{1}$
}

\begin{abstract}
Resumo: Este artigo apresenta como a ferramenta computacional de Modelagem e Simulação Humana contextualizada pela Análise Ergonômica do Trabalho (AET) e pela análise da Atividade Futura Possível pode auxiliar nos processos de projeto de postos de trabalho. São analisados dois estudos de caso nos quais a Simulação Humana foi empregada com auxílio do software Jack. O primeiro estudo aborda a concepção de um balcão de atendimento em uma empresa pública de serviços postais. O segundo apresenta o desenvolvimento de uma estação de trabalho de abastecimento de agulhas cirúrgicas em uma empresa de manufatura de produtos relacionados às áreas de saúde e higiene. A partir dos resultados dos estudos de caso, são explicitadas as contribuições e desafios da utilização dessa tecnologia em projetos visando equacionar as questões de saúde e produtividade. $\mathrm{O}$ uso da simulação integrada ao processo de intervenção da AET permitiu melhorar a antecipação das futuras atividades prováveis das novas situações de trabalho e auxiliou a integração e comunicação dos atores envolvidos nesses processos sociais.
\end{abstract}

Palavras-chave: Simulação humana digital. Projeto de postos de trabalho. Ergonomia.

\begin{abstract}
This paper investigates a computational tool for Human Modeling and Simulation contextualized by Ergonomic Analysis of Work (EAW) and future work activity forecasting that can assist in the design processes of workplaces. Two case studies using Human Simulation was employed and the software Jack were analyzed. The first study presents the design of a counter in a public post office. The second shows the development of a workstation for the supply of surgical needles in a company that manufactures hygiene and healthcare products. The results of the case studies show the contributions and challenges of using this design technology aiming to solve problems related to health and productivity. The use of simulation combined with EAW helped to improve future work activity forecasting of new work situations and helped the integration and communication of the actors involved in these social processes.
\end{abstract}

Keywords: Digital human simulation. Workplace design. Ergonomics.

\section{Introdução}

A simulação humana em projetos de postos de trabalho tem conquistado espaço em grandes empresas e instituições. Os principais benefícios advindos do uso dessa tecnologia são: ganho de tempo no processo de projeto, auxílio na comunicação entre os diferentes atores do projeto e entre projetistas e usuários, e a antecipação das considerações que envolvem a possível atividade futura de trabalho (FEYEN et al., 2000; BRAATZ et al. 2002).

No Brasil, essa tecnologia ainda está em estágio inicial de difusão. Poucas empresas e instituições adotam este ferramental de forma estruturada, sendo comum a aquisição da licença do software e posterior uso em aplicações específicas e isoladas.

A incorporação da perspectiva da atividade por meio de um método de análise do trabalho é um diferencial apresentado neste estudo e faz-se uma correlação entre as principais linhas da ergonomia e seus instrumentos. Também são feitas considerações sobre os limites de uso dessas tecnologias, e a grande demanda por métodos eficazes e usuários capacitados para sua operação.

O objetivo deste trabalho é mostrar como a simulação e modelagem humana pode auxiliar no

\footnotetext{
${ }^{1}$ Grupo de Pesquisa Ensino e Extensão Ergo\&Ação, Departamento de Engenharia de Produção, Universidade Federal de São Carlos - UFSCar, Rod. Washington Luís, Km 235, SP-310, CEP 13565-905, São Carlos, SP, Brasil, e-mails: braatz@ dep.ufscar. br; menegon@dep.ufscar.br; andreaf@dep.ufscar.br; tonin@dep.ufscar.br
} 
processo de projeto de postos de trabalho e quais os referenciais teóricos utilizados como base de fundamentação.

\section{Aspectos teóricos}

A aplicação de simulação no processo de projeto de engenharia, durante um estudo ergonômico, deve ter fundamentação conceitual e metodológica para obter resultados efetivos (DANIELLOU, 2002a).

Neste contexto, buscou-se uma abordagem participativa favorecendo um espaço de discussão e de construção de consensos, acordos e deliberações no decurso do projeto. Dessa forma, foram articulados objetivos de busca de ação sobre a realidade por meio de confrontações de diferentes mundos-objeto (BUCCIARELLI, 1994). Tal compreensão demanda mecanismos que permitam a integração dos diferentes atores envolvidos no projeto (operadores dos postos de trabalho, chefias, gerências, pesquisadores, entre outros) para a construção coletiva do problema e do campo de soluções possíveis, partindo da realidade da situação e considerando suas diferentes interpretações, criando assim ambientes propícios para tomadas de decisões e validações (MENEGON, 2003).

Para Daniellou (1995), os elementos do modelo da racionalidade técnica (fundamentado na teoria de sistemas e na resolução de problemas) e do modelo de negociação dos constrangimentos (o qual considera que a atividade de projeto possui um caráter desestruturado e que os artefatos técnicos são socialmente construídos) podem ser trabalhados em conjunto. A prática da ergonomia deve não somente descrever os processos de concepção, mas os influenciar para favorecer uma concepção das situações de trabalho eficaz (relativo à eficácia da ação produtiva) e compatível com a saúde dos trabalhadores. $\mathrm{O}$ fornecimento de dados técnicos sobre o funcionamento do homem aos projetistas tem a sua importância, mas aparece como elemento secundário em relação a uma ação precoce da ergonomia no que diz respeito aos diferentes atores de concepção, por permitir uma discussão ampla do conjunto dos objetivos do projeto.

\section{Aspectos metodológicos}

O auxílio da modelagem e simulação em processos de projeto de postos de trabalho é relatado aqui em duas situações distintas: a primeira, inserida em um projeto de ergonomia em que foi aplicada a Análise Ergonômica do Trabalho (AET). A segunda situação surge como resultado de um programa perene de levantamento e análise de riscos ergonômicos por meio da aplicação do instrumento Ergo Job Analyser, desenvolvido internamente à empresa. Tal instrumento, detalhado por Bertoncello et al. (2004), é característico da corrente americana da ergonomia, Human Factors, que tem como foco a compreensão da natureza das interações entre o homem e o artefato, incluindo uma variedade de produtos, processos e ambientes.

Além disso, conforme a perspectiva de Montmollin (2005), a ergonomia centrada na componente humana (Human Factors) centra-se nas duas maiores exigências de todo procedimento científico: a generalização e a medida quantitativa. Ainda segundo o autor, a lista das componentes humanas, tradicionalmente estudadas por esta corrente, enfatiza os itens: posturas e movimentos, em especial as bases biomecânicas, fisiológicas e antropométricas.

Nesse sentido, a ferramenta computacional de modelagem e simulação humana utilizada nesta pesquisa também possui maior influência da Human Factors, na medida em que traduz a interação humanoambiente de forma quantitativa, enfatizando suas considerações sobre aspectos físicos e atribuindo uma menor relevância aos aspectos organizacionais e cognitivos da futura atividade.

Para Ziolek e Kruithof (2000), o processo de modelagem e simulação humana pode ser dividido em três grandes áreas: o ambiente (incluindo desenhos em CAD - computer aided design - projeto auxiliado por computador), os manequins (ou modelos digitais humanos construídos com dados antropométricos) e as análises (possíveis a partir da simulação).

O método utilizado nos estudos de caso refere-se a um conjunto de conhecimentos utilizados que possibilita análises de diversos componentes que devem estar presentes na simulação e na criação de uma síntese, global e coerente, a partir dos resultados gerados.

Considerando a divisão proposta por Ziolek e Kruithof (2000), pode-se caracterizar que: o ambiente não é somente resultado de desenhos e dados geométricos, mas também da atividade realizada pelos trabalhadores (em contraposição à tarefa prescrita pela organização). A atividade também influencia a simulação humana com relação às ações e posturas que os manequins realizam em seus postos de trabalho. Os manequins derivam da modelagem humana e dos dados antropométricos, e as análises são definidas pela própria simulação humana e pelo software utilizado. Neste contexto, busca-se evidenciar a situação de simulação (como objeto intermediário) em contraposição à simulação da situação, a qual modela por meio de abstrações, e que implica na redução da complexidade (BÉGUIN; WELL-FASSINA, 2002).

\subsection{Análise da atividade}

A análise da atividade permite que o projeto busque contemplar o trabalho real a ser realizado no futuro posto de trabalho. Para isto, utiliza-se a análise de situações de referência, caracterização das atividades e a participação efetiva, durante o projeto, de 
trabalhadores com competências diversas semelhantes às dos futuros operadores (DANIELLOU, 2002b).

Dessa forma, além das tarefas prescritas pela organização, existe uma incorporação à modelagem das relações entre a atividade de trabalho, saúde e produtividade. Isto é, a simulação deverá considerar o modo operatório, compreendido aqui como o compromisso do operador frente aos meios de trabalho, objetivos de produção, resultados produzidos e o estado interno do trabalhador (DANIELLOU, 2005). No entanto, considera-se que tal incorporação é limitada pelo software que não compreende as dimensões cognitivas do trabalho em sua interface.

\subsection{Modelagem humana e antropometria}

O processo de modelagem humana é determinante para a eficiência da simulação, especialmente no contexto dos estudos de caso apresentados a seguir, nos quais é aplicado como ferramenta de projeto (no sentido de antecipação de necessidades antropométricas) e como objeto intermediário para participação na construção e validação dos cenários evolutivos. Para que os resultados da simulação possam ser considerados válidos, é necessário que a modelagem seja considera apta e confiável.

De forma simplificada, pode-se afirmar que os dados que abastecem a modelagem humana são provenientes da antropometria. De acordo com Menegon et al. (2002), as questões antropométricas influenciam aspectos relacionados à fisiologia e à psicologia do conforto e da percepção sendo, portanto, relevantes para a concepção e dimensionamento dos produtos, ambientes e postos de trabalho, de maneira a colaborar na busca pela segurança e conforto dos usuários.

É de fundamental importância que os dados antropométricos utilizados sejam aderentes às características morfológicas dos usuários dos postos de trabalho sob análise e projeto. Nesse sentido, o Brasil enfrenta a mesma dificuldade encontrada na grande maioria dos países que atuam com modelagem humana, isto é, a falta de levantamentos antropométricos criteriosos e atualizados, exceção para os Estados Unidos (pioneiro nessas pesquisas) e a Alemanha, sendo este último o país que possui a base de dados mais atual, apta à aplicação em modelagem humana computacional e disponível comercialmente (SIZEGERMANY, 2010). No entanto, o quadro de escassez brasileira foi atenuado após uma pesquisa antropométrica realizada no ano de 2001 em uma empresa aeronáutica do Estado de São Paulo (MENEGON et al., 2002). Tal pesquisa possuiu um grande diferencial na definição das variáveis, visto que os segmentos e proporções foram definidos com base na interface de entrada de dados do software utilizado. Normalmente, os dados precisam ser adaptados para conceber a modelagem, comprometendo dessa maneira a confecção de modelos digitais humanos aptos para análises (JONES, 1997).

Todavia, é conveniente ressaltar dois problemas acerca deste assunto: a) que no Brasil, assim como em muito outros países, há uma carência muito grande de pesquisas antropométricas que ultrapassem os limites de levantamentos com populações específicas - espacialmente localizadas; e b) apesar da existência de equipamentos de grande precisão e rapidez para aquisição de dados antropométricos (sobretudo scanner 3D), os principais softwares comerciais ainda não estão aptos ao uso desta rica fonte de dados.

A partir dos dados é possível a construção dos modelos digitais humanos, sendo que o software Jack considera 24 variáveis antropométricas e o sexo do manequim. A validação dessa modelagem foi apresentada por Braatz et al. (2002) em um estudo comparativo entre as medidas do manequim digital e as medidas referentes ao levantamento antropométrico, explicando inclusive as razões das divergências encontradas e as dificuldades em aplicar dados bidimensionais em modelos humanos tridimensionais. Concluída a construção e validação dos modelos digitais humanos é possível iniciar de forma mais consistente a etapa de simulação.

\subsection{Simulação humana e análises}

Na perspectiva desta pesquisa, o objetivo da simulação humana é dar suporte ao processo de projeto, tanto como objeto intermediário, quanto para a antecipação dos futuros constrangimentos possíveis.

A intermediação dos diferentes agentes durante a projetação pode ser auxiliada pela simulação humana na medida em que facilita a compreensão dos diferentes detalhes do projeto, permitindo sua visualização numa representação tridimensional, antecipando suas possíveis utilizações e as aplicações ainda em ambiente digital. Além deste ferramental, esta etapa utiliza-se de croquis, desenhos CAD com plantas e perspectivas, maquetes físicas (modelos em escala) e mock-up (modelo em tamanho natural), além de um memorial descritivo acerca das características do projeto e suas futuras aplicações, entre outros recursos. As novas tecnologias da computação gráfica e dos softwares de engenharia, no entanto, não tornarão desnecessários tais instrumentos, mas ser-lhes-ão complementares.

\subsection{Caracterização do software aplicado}

O software Jack é uma ferramenta gráfica que permite simulações de situações reais de trabalho, visando o ambiente e, principalmente, a figura humana. Elaborado na Universidade da Pensilvânia, Jack teve sua marca registrada comprada e hoje é parte 
integrante das soluções de computação gráfica para engenharia da UGS Siemens.

Antecipando questões ergonômicas e de usabilidade, o processo de projeto torna-se mais ágil, seguro e com maiores chances de sucesso. A etapa de prototipagem física dificilmente pode ser descartada, no entanto, seus custos e tempo demandado podem ser consideravelmente reduzidos utilizando essa etapa para verificação e validação de outros detalhes, visto que uma parte dos problemas que seriam encontrados já foram diagnosticados e solucionados durante a prototipagem digital.

Depois da simulação é possível passar para a etapa de análise. A principal análise derivada do software é a análise biomecânica. Pela observação e análise de postos de trabalho, é possível identificar posturas e movimentos (considerando seu tempo de duração e repetições) que ofereçam riscos de danos à saúde do trabalhador. No Jack, essas ferramentas de análise são embasadas por diferentes estudos, permitindo que a análise seja feita com maior rapidez e precisão pela interação homem-ambiente, e possibilitando que alguns dados sejam obtidos automaticamente. Os principais métodos e análises disponíveis no Jack 4.1 são:

- RULA (Rapid Upper Limb Assessment);

- Equação de Carregamento da NIOSH (National Institute for Occupational Safety and Health);

- OWAS (Ovako Working Posture Analysing System);

- Análise de fadiga;

- Gasto de energia metabólica.

As análises realizadas pelo software possibilitam a construção de relatórios com informações quantitativas e estudos comparativos de situações com características diferentes (variabilidade da empresa) considerando a diversidade da população presente no ambiente em questão (variabilidade antropométrica do indivíduo).

A definição pela utilização de um software específico, e não outro similar, se deve ao fato da parceria existente entre os grupos de pesquisa SimuCAD e Ergo\&Ação (DEP/UFSCar) com a UGS Siemens.

\section{Estudos de caso}

Os casos utilizados neste artigo são derivados de projetos de extensão do grupo de pesquisa Ergo\&Ação entre os anos de 2003 e 2005. Ambos são postos de trabalho, sendo o primeiro em uma empresa do setor de serviços e o segundo em uma empresa de manufatura. Nos dois projetos a versão utilizada para a simulação foi o Jack $2.2 \mathrm{i}$, pacote básico (Classic Jack), sendo os ambientes modelados em AutoCAD (Autodesk) e posteriormente importados pelo Jack.

\subsection{Estudo de caso 1: projeto de um balcão de atendimento}

A empresa em que se situa o primeiro estudo de caso desse trabalho pode ser caracterizada como uma das maiores empresas públicas brasileiras, principalmente pela difusão no território nacional e pelo número de empregados que possui.

A demanda para intervenção ergonômica nessa empresa, como detalha Fontes et al. (2006), parte como resposta a diversas notificações trabalhistas que fazem referência ao cumprimento de normas de segurança e medicina do trabalho previstas na Consolidação das Leis Trabalhistas (CLT) e da Norma Regulamentadora 17 do Ministério do Trabalho e Emprego (BRASIL, 1990), especialmente os artigos 156, 157 e 199 da CLT e os itens 17.1, 17.3, 17.4, 17.5 e 17.6 da NR17.

As demandas indicadas pela empresa tratavam-se da: inadequação do mobiliário existente, da introdução dos novos sistemas informatizados, do monitoramento eletrônico do trabalho e da organização do trabalho de uma forma geral (FONTES et al., 2006).

Analisando-se os atestados médicos encaminhados, constataram-se dois grandes campos de problemas: Doenças do sistema musculoesquelético e transtornos mentais. As queixas relacionadas aos constrangimentos físicos estavam fundamentalmente relacionadas às posturas adotadas pelo atendente em consequência das limitações impostas pelo mobiliário. Com relação aos transtornos mentais, estes estavam relacionadas com a exigência de atenção (carga cognitiva) e de responsabilidade (carga psíquica).

O projeto de ergonomia contratado via licitação previa atender às demandas por meio da realização de AET e projeto de dispositivos resultantes dessas análises. Para execução das análises e desenvolvimento dos projetos, foram destacadas pessoas de dentro da empresa, provenientes de diferentes setores, gerências e regiões geográficas para acompanhamento, aprendizagem e colaboração durante todo o projeto de intervenção ergonômica, formando, conjuntamente com o grupo de pesquisa, um grupo de trabalho para análise e projeto.

A partir do diagnóstico da situação existente o projeto foi direcionado para duas propostas (FONTES et al., 2006): i) adequação do balcão existente (adaptação sem grandes modificações estruturais); e ii) construção de um novo balcão de atendimento (novo desenho). Destaca-se que o presente artigo descreverá apenas o processo de desenvolvimento da segunda proposta.

A intervenção ergonômica foi realizada no período de maio de 2003 a dezembro de 2004 e constituiu-se das seguintes fases:

- Análise da demanda e do contexto (entendimento do contexto e explicitação por 
parte dos demandantes dos problemas a serem solucionados);

- Análise da tarefa (entendimento do que o trabalhador deve realizar e as condições ambientais, técnicas e organizacionais desta realização. É fundamental conhecer como o trabalho é prescrito no interior da organização);

- Análise da atividade (entendimento do que o trabalhador, efetivamente, realiza para obter os resultados esperados pela tarefa);

- Diagnóstico da situação existente;

- Desenvolvimento de conceitos projetuais:

- Hierarquização das soluções, restrições de adaptabilidade e interação com os usuários do posto de trabalho;

- Projeto do móvel;

- Simulações digitais

- Implantação das melhorias:

- Especificações técnicas;

- Construção do protótipo físico e implantação

- Validação (confrontação entre o objeto implantado e sua interação com o usuário) com avaliações, aplicações de questionários de percepção com os usuários e modificações.

- Manual de boas práticas (manual para o trabalhador tomar conhecimento das melhorias implantadas em seu posto juntamente com esclarecimentos sobre a usabilidade deste).

A proposta conceitual de um novo balcão nasceu da análise da atividade dos usuários, do diagnóstico e dos resultados das análises biomecânicas para cada modelo de balcão existente atualmente. O projeto passou por algumas discussões e refinamentos com o grupo de trabalho até a confecção de protótipos. Os requisitos de projeto para o desenho do novo balcão foram discutidos a partir das características desejáveis e possuíram as seguintes categorias de análise:

- Forma da superfície de trabalho;

- Cadeira;

- Altura do tampo do balcão visando trabalho em pé e sentado;

- Apoio para membros superiores;

- Apoio para membros inferiores;

- Móveis auxiliares (gaveteiro e guarda de objetos e produtos);

- Movimentação de objetos (fluxo de materiais);

- Relação cliente/atendente e entre atendentes;

- Segurança de produtos, numerário e pessoal da atendente.

Foram realizadas inúmeras simulações e análises com o software Jack apontando a geometria favorável para contemplar os requisitos desejados em concordância com o bem-estar do trabalhador.
Em todas as simulações e análises, foram utilizados o manequim masculino percentil 95, como indivíduo extremo do limite superior, e o manequim feminino percentil 05, visando o limite inferior. Assim, buscou-se projetar um posto de trabalho apto para atender à maior parte da população sob estudo. A seguir apresenta-se como a tecnologia de modelagem e de simulação humana contribuiu para cada categoria de análise.

$\mathrm{Na}$ caracterização dos fatores de risco da tarefa, foram realizadas filmagens dos processos de trabalho. Foram identificadas 13 categorias de produtos e, dentro destas, 23 processos distintos. Durante as análises, percebeu-se que a tarefa de atendimento ao cliente poderia ser dividida em etapas conforme a predominância destas em todas as atividades realizadas pelo atendente. Sendo assim, verificou-se o posicionamento de cada segmento corporal durante as seguintes etapas fragmentadas: pega/entrega de material do cliente; leitura/escrita em objeto postal; carimbação; pega de caixa vazia; colocação de objeto postado em caixa específica; digitação; operação com numerário; organização de documentos; e organização de produtos.

O espaço de trabalho abordado é constituído especialmente pelo guichê ou balcão de atendimento onde são colocados os dispositivos técnicos - ver Figura 1. Estes podem ser categorizados em mobiliário (balcão de atendimento), equipamentos (máquina autenticadora, balança grande, balança pequena, teclado Pin, equipamento "Sara", leitor de código de barras de cheques, leitor de código de barras de etiquetas, monitor, mouse, teclado e CPU) e acessórios (almofada para carimbo, calculadora, carimbos, fita ou fita com aplicador, grampeador, moedeiro, molhador de selos, pasta de selos, lençol de carimbo ou de borracha).

A forma da superfície de trabalho é determinante para a atividade desenvolvida nos balcões de atendimento. Um dos principais aspectos influenciados é o espaço de trabalho disponível para os equipamentos e objetos manuseados, sendo que a falta de espaço pode obrigar o atendente à adoção de posturas de risco e aumentar a possibilidade de queda de objetos ou equipamentos. Tais pontos estão diretamente relacionados à origem da demanda.

A adoção da forma em "U" para o tampo do balcão (em contraposição a forma em "L" atual) buscou atender a essa demanda de espaço, que, em consonância com a liberação da parte inferior do tampo, retirando o gaveteiro existente nos balcões atuais, permitiu ao atendente o giro de 180 graus com diversas possibilidades de regulação para escolha do modo operatório pretendido, além de contemplar usuários destros e sinistros. Por meio de simulações das futuras atividades prováveis foi possível observar e avaliar questões como a relação de profundidade do tampo com o alcance do atendente, principalmente 


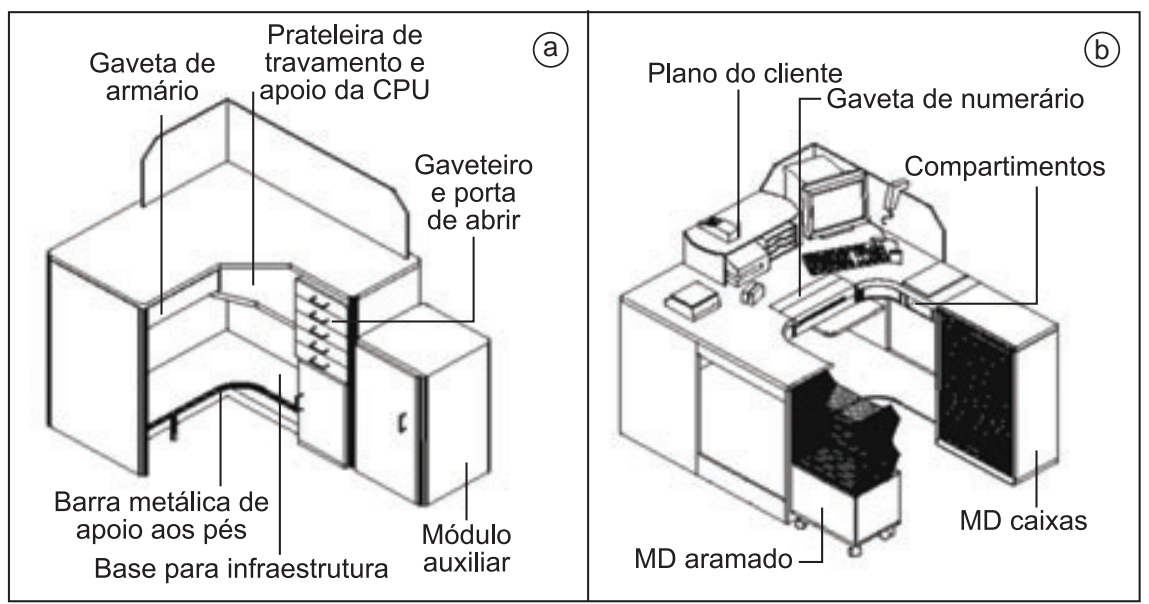

Figura 1. Perspectivas dos balcões de atendimento existentes (a) e novo (b) (FONTES et al., 2006).

no que tange ao manequim digital feminino percentil 5 e sua interação com os clientes e objetos.

Outra importante contribuição da simulação humana nessa categoria de análise foi a verificação da disposição do grande número de equipamentos utilizados e o impacto no espaço disponível. Com o auxílio do grupo de trabalho e de usuários do posto que conhecem o cotidiano dessa função, foi possível estabelecer uma possível configuração de como o posto de trabalho poderia ser organizado. No entanto, faz-se necessário reforçar a importância de permitir aos trabalhadores que organizem conforme seus próprios modos operatórios o seu posto de trabalho, aumentando dessa forma o espaço de regulação. Destaca-se que, a partir da forma em "U" da superfície de trabalho, outros parâmetros foram influenciados, como a necessidade de se adotar uma cadeira giratória e com rodízios deslizantes para permitir o giro e afastamento facilitado do posto.

Nesse sentido, compondo o novo posto de trabalho, juntamente com o balcão, a cadeira foi um dos principais itens avaliados, pois também impacta diretamente em uma série de outros aspectos, como a percepção do conforto de seu usuário, altura da superfície de trabalho, apoio para membros superiores e inferiores, relação cliente/atendente, segurança pessoal do atendente, entre outros. Como a cadeira é um objeto bem estabelecido no mercado, com inúmeros fornecedores e características, optou-se por buscar dentre as opções disponíveis as características desejáveis para compor com o balcão. Dessa forma, a especificação criada e utilizada nas simulações foi para uma cadeira alta (tipo caixa) com o maior percurso de ajuste de altura de assento disponível, apoios ajustáveis de costas e braços, rodízios fabricados com materiais de alto desempenho de deslizamento e outras características desejáveis, como por exemplo, sistemas de fácil ajuste por parte dos usuários, os quais possam ser manipulados rapidamente, sem o uso de ferramentas ou manual de instrução.

Para a definição da altura do tampo do balcão, os manequins foram posicionados nas posturas em pé e sentada. Utilizou-se como alvo primário a altura do cotovelo do manequim feminino (extremo inferior), evitando que a altura do novo plano de trabalho exija movimentos extremos dos membros superiores desses usuários durante a execução da tarefa. Em seguida, verificou-se, por meio de simulações, o rebatimento da altura estabelecida para os manequins do extremo superior masculino, tanto na postura em pé quanto na sentada.

Na concepção e avaliação do apoio para os membros superiores, antecipou-se a futura atividade possível do trabalhador, simulando os equipamentos a serem incorporados, rotinas realizadas atualmente $\mathrm{e}$ outras demandas. Dessa forma, o objetivo era avaliar o espaço necessário para o apoio de braços, punhos e mãos, sem restringir ou dificultar as atividades realizadas. Foram utilizados diferentes cenários (testando combinações de implantação de dispositivos técnicos) e simulados com os manequins dos dois extremos e para as posturas em pé e sentada.

Visando o apoio dos membros inferiores, foi desenvolvida uma superfície denominada de "tablado" para o apoio plantar dos pés. Tal estrutura possui ajuste de altura e acompanha a forma em "U" da superfície de trabalho, propiciando o giro em $180^{\circ} \mathrm{com}$ o apoio dos membros inferiores e conforto postural. A simulação com os manequins de percentis extremos pôde verificar e validar a faixa necessária de ajuste de altura do tablado - ver Figura 2 - e sua relação com o ajuste de altura do assento, evitando, dessa forma, que as pernas fiquem em balanço. Tal postura ocasiona um aumento da pressão exercida pelo corpo do atendente sobre a cadeira e, consequentemente, um aumento do desconforto. 


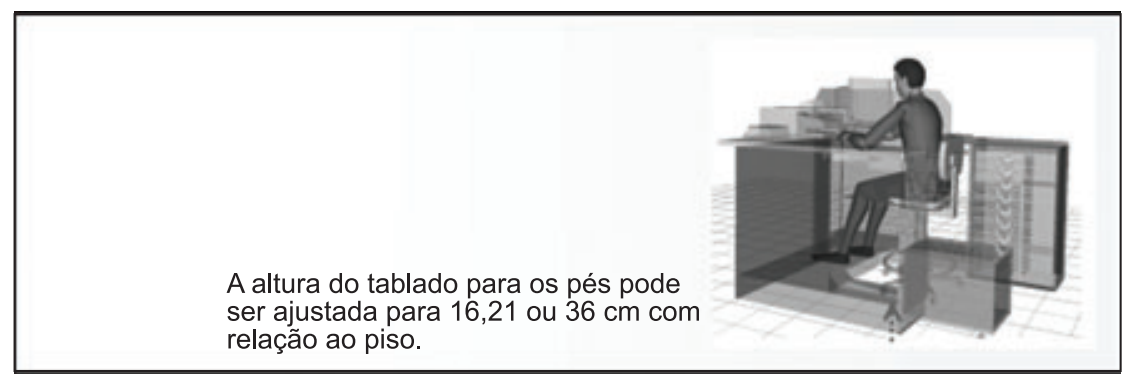

Figura 2. Alturas de ajuste do tablado para apoio dos pés.

Visando a movimentação do usuário do posto, foi determinada a liberação da parte inferior do tampo por meio da retirada do gaveteiro e da prateleira de apoio da CPU horizontal. As simulações objetivaram validar a melhora no giro da cadeira, movimentação das pernas, entrada e saída do usuário no guichê, facilidade de uso do tablado para apoio dos pés e alternância de posturas em pé e sentada. Foram utilizados especialmente manequins do extremo superior masculino para avaliar o espaço liberado, verificando se o espaço livre estaria adequado para usuários com maiores dimensões corporais, e se também ofereceria um bom espaço livre para usuários com menores dimensões. A retirada do gaveteiro de armazenamento de acessórios e produtos gerou a necessidade de desenvolver móveis auxiliares. A simulação auxiliou na construção de cenários com diferentes propostas, nos quais se buscou compreender as novas relações entre o usuário e esses artefatos, especialmente do ponto de vista antropométrico.

O estudo do fluxo e movimentação dos materiais foi de extrema importância para a concepção de um posto de trabalho que facilitasse e minimizasse esforços físicos por parte do atendente. O principal objetivo foi definir e simular uma linha principal de fluxo, para que, nos casos de objetos pesados, estes pudessem ser apenas arrastados, sem a necessidade de levantar ou manusear tais objetos, o que obrigaria um desgaste físico com riscos de lesões. Para permitir a linha contínua de fluxo e a movimentação facilitada, foi necessária a liberação de um dos lados do balcão, isto é, sem a presença de equipamentos ou objetos fixos, com exceção da balança, que é um equipamento utilizado na grande parte dos materiais manuseados. As principais análises dessa categoria tiveram como foco a utilização do percentil inferior feminino, simulando situações extremas de alcance e manuseio de materiais de grandes dimensões.

Para antecipar e avaliar as condições de interação entre cliente e atendente, foram simulados diversos cenários, com variação de percentis nas duas funções. A situação mais crítica encontrada foi no cenário em que o manequim extremo inferior feminino executava a função de atendente em posição sentada e o extremo superior masculino executava a função de cliente na posição em pé. A construção dos cenários levou em conta as categorias de análise contato visual e sentimento de inferioridade, comumente encontradas na literatura sobre interação consumidor/fornecedor. A relação entre atendentes, com enfoque para a facilidade de comunicação, pôde ser constatada pelas categorias de análise de campo visual e distância entre manequins. Foram modelados arranjos com mais de um balcão, possibilitando simulações de atendimentos conjuntos. Essas simulações determinaram a forma e a altura do anteparo entre guichês.

Para melhorar a percepção de segurança pessoal, de produtos e de numerário para os trabalhadores, foram feitas simulações enfocando especialmente a gaveta de numerário. Essa demanda ficou evidente nos questionários de percepção pelo fato do aumento do montante de dinheiro em circulação dentro das unidades e o receio de assaltos. Para melhorar essa situação no novo balcão, foi especificada uma gaveta de numerário metálica, embutida e com abertura para cima (tipo tampa) via acionamento pelo sistema informatizado. $\mathrm{O}$ fechamento e trancamento desse sistema são obtidos por meio do movimento de rotação da tampa para a posição inicial (sem necessidade de chaves e com diminuição da força aplicada). As simulações confirmaram que: para realizar a abertura não há mais a necessidade de afastamento e, quando fechada, sua superfície pode ser usada para outros trabalhos. Outra característica da nova gaveta, validada pela simulação, foi: no momento em que se encontra aberta, sua tampa serve como anteparo ao campo de visão do cliente e redução do risco de acesso ao numerário. Tais vantagens foram confirmadas em simulações de rotinas de trabalho, focando as categorias de campo visual do cliente e zona de alcance.

Finalizando as categorias de análise, um dos aspectos que ficou evidente nas entrevistas e questionários de percepção realizados com funcionários das unidades foi a questão da segurança de produtos, de numerário e segurança pessoal. O principal foco desse aspecto foi a gaveta de numerário, que, apesar de sempre existir, sofreu um agravamento com a recente 
função de correspondente bancária incorporada pela empresa nos últimos anos. Tal fato veio a aumentar o montante de dinheiro em circulação dentro das unidades e o receio por parte dos funcionários de furtos. As gavetas existentes são feitas de madeira, sendo consideradas pesadas, grandes e obrigam que o atendente se afaste do balcão para poder abri-la, além de expor diretamente seu conteúdo às pessoas que estão do outro lado do balcão.

Apesar de a prescrição solicitar que todas as vezes que um atendente se retire do balcão ele deva fechar e trancar a gaveta, levando a chave, a observação do trabalho real mostrou que isso não era praticado, principalmente pelas constantes movimentações de curto deslocamento realizadas ao longo do dia. Para melhorar essa situação, o novo balcão foi especificado com uma gaveta de numerário metálica, embutida e com abertura para cima via acionamento pelo sistema. Dessa forma, a gaveta somente é aberta por meio de comando do sistema em situações específicas (momento de receber numerário e entregar troco), e para trancá-la basta fechar a gaveta (sem esforço físico devido ao baixo peso da tampa de metal).

As simulações confirmaram que para realizar a abertura não há mais a necessidade de se afastar e que, quando está fechada, sua superfície pode ser usada para outros trabalhos. Outra vantagem dessa gaveta é que, quando se encontra aberta, sua tampa serve como obstáculo ao campo de visão e alcance de quem está do lado de fora do balcão, propiciando maior segurança para os funcionários. Tais vantagens foram confirmadas em simulações de rotinas, focando o campo visual do cliente e envelopes de alcance.

Algumas das simulações e análises apresentadas estão ilustradas na Figura 3.

A partir da prototipagem digital, foi construída a primeira versão física do novo balcão de atendimento. Desta forma, o móvel concebido para prototipagem física confirmou diversos conceitos com maior confiabilidade para as especificações técnicas, como simetria, liberação da parte inferior do balcão, proximidade dos equipamentos de uso frequente, percepção de segurança proporcionada pela gaveta de numerário, entre outros, conforme a Figura 4.

\subsection{Estudo de caso 2: projeto de posto de trabalho em manufatura}

O segundo caso ocorreu em uma empresa multinacional de grande porte que atua na fabricação de produtos cirúrgico-hospitalares, de primeiros socorros, para higiene de crianças, produtos de higiene oral, farmacêuticos, de higiene feminina e outros produtos destinados à saúde dos consumidores. Com
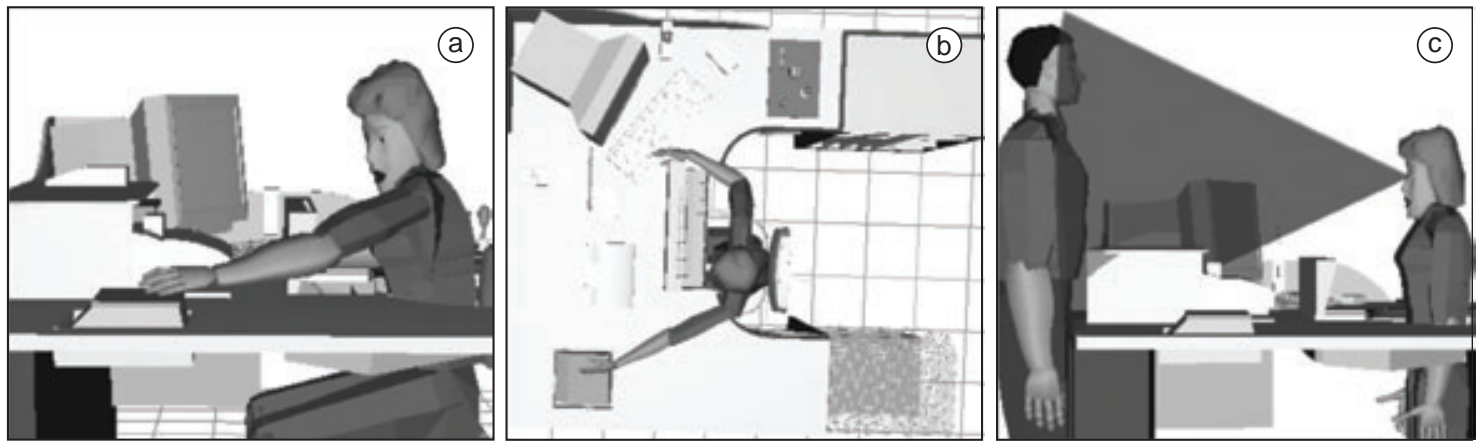

Figura 3. Simulações e análises realizadas durante desenvolvimento de projeto conceitual: a) zonas de alcance, b) superfície de trabalho, e c) relação cliente/atendente).
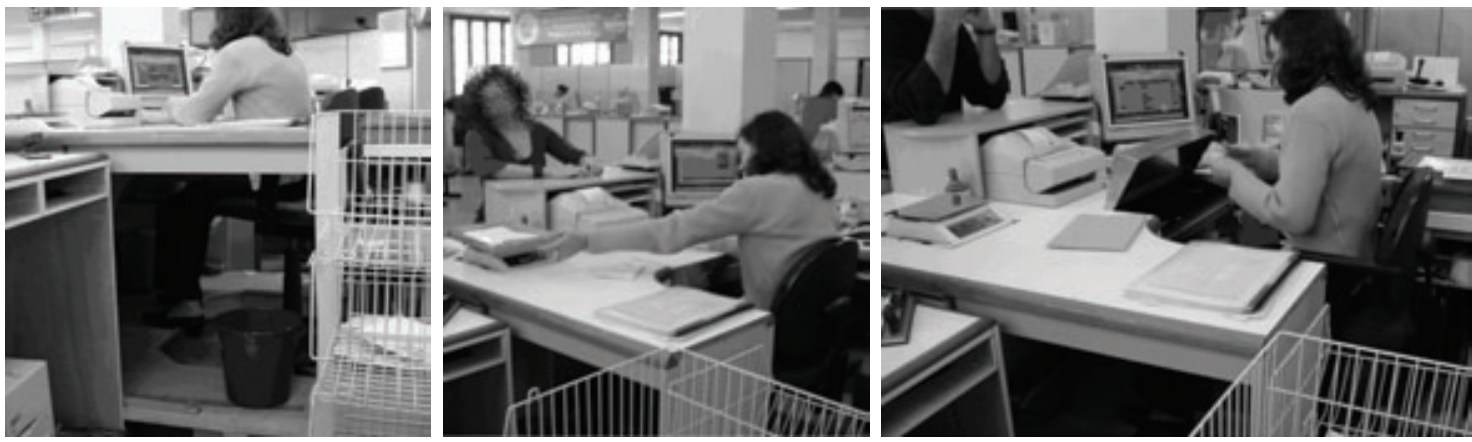

Figura 4. Prototipagem física de balcão de atendimento. 
a matriz localizada nos Estados Unidos, atualmente essa empresa possui unidades produtivas em 51 países, estando no Brasil desde 1933. A atual planta industrial está instalada no interior do Estado de São Paulo com cerca de 4.500 funcionários.

A demanda para o projeto abordado neste trabalho surge a partir de uma parceria entre a empresa e o grupo Ergo\&Ação no que se refere a aplicar, tratar e melhorar um instrumento de análise ergonômica, o Ergo Job Analyser (EJA) e, posteriormente, desenvolver propostas conceituais para as situações críticas.

$\mathrm{O}$ posto de manufatura projetado consiste numa estação de trabalho de abastecimento de suportes (conhecidos como pentes) com agulhas cirúrgicas visando posterior processamento químico, sendo classificado como de alto potencial de risco devido a sua repetitividade, movimentos de alta precisão e com grande demanda de atenção.

Basicamente as tarefas executadas neste posto de trabalho são: apanhar o pente vazio (posicionado no lado esquerdo da bancada) e posicioná-lo no dispositivo localizado na frente do operador; pegar uma caixa de agulhas (sob o tampo da mesa) e dispor cerca de 30 agulhas ordenadamente sobre a mesa; pinçar manualmente cada agulha e posicioná-la no pente (no qual há pequenas ranhuras nas quais estas se encaixam); preencher todas as ranhuras e, então, travar o pente (o qual conta com um dispositivo que trava as agulhas nas ranhuras). Por fim, o operador posiciona o pente carregado de agulhas no suporte localizado à sua direita. A Figura 5 ilustra o posto de trabalho antes da intervenção.

Todo o processo de projeto durou cerca de dois anos e possuiu as seguintes fases:

- Confecção da análise ergonômica com o EJA;

- Análise da atividade da situação com alto potencial de risco;

- Decomposição do novo conceito do posto de trabalho em vários subsistemas;

- Início do processo de projeto do posto considerando as restrições de projeto e desenvolvendo os subsistemas paralelamente;
- Confecção de mock-ups (modelo em escala natural) para experimentação e validação dos pressupostos conceituais referentes aos principais subsistemas;

- Modelagem e simulação humana digital do sistema global;

- Análise ergonômica do conceito global em ambiente digital com o instrumento EJA;

- Finalização das especificações técnicas.

O instrumento EJA, segundo Bertoncello et al. (2004), foi desenvolvido para avaliar estações de trabalho a partir da análise de posturas corporais, frequência de movimentos em atividades similares ou distintas, carga despendida, entre outros fatores. Este instrumento considera não apenas o movimento de cada articulação corporal durante cada atividade, mas solicita que se numerem os movimentos em uma espécie de contagem total por dia. A ferramenta

[...] indica amplitudes diferenciadas de movimentos [...] assim, os movimentos de cada segmento corporal são somados de acordo com a amplitude específica dos mesmos, em cada turno de trabalho, respeitando também a questão biarticular (ombro direito e ombro esquerdo somados separados, por exemplo), quando há. (BERTONCELLO et al., 2004, p. 3).

$\mathrm{O}$ resultado dado por esta ferramenta é a quantificação de risco associado aos postos de trabalho. Esta quantificação auxilia na definição de prioridades para execução de melhorias ergonômicas. É importante salientar que, o mesmo instrumento que gerou a demanda, foi utilizado para validar a proposta final do projeto em ambiente digital.

O projeto foi caracterizado pela evolução conceitual dos subsistemas que, para um melhor desenvolvimento, foi dividido em recortes, conforme ilustrado na Figura 6.

Esses recortes foram necessários para que questões fundamentais e prioritárias pudessem ser analisadas e avaliadas separadamente em diferentes locais e intervalo de tempo. Assim, questões envolvendo eletrônica e automação dos subsistemas "canal

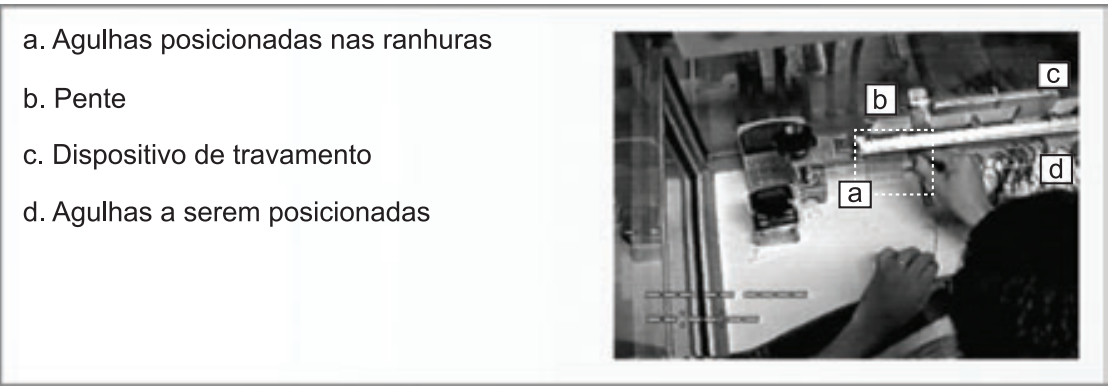

Figura 5. Posto de trabalho antes da intervenção. 
e esteira" e "pinça e pente", que eram a base fundamental da solução, puderam ser desenvolvidos e prototipados nos primeiros meses de projeto, para que, sendo validados, fornecessem estabilidade para a continuidade do projeto. Na Figura 7, são apresentados dois protótipos desenvolvidos e validados. A Figura $7 \mathrm{~b}$ mostra o processo de validação com um funcionário da empresa, alocado no posto equivalente atual.

Com base nas análises resultantes dos desenvolvimentos iniciais dos subsistemas, foi possível iniciar a construção de um conceito global com o auxílio de ferramentas de computação gráfica, em especial a simulação humana. Os requisitos de projeto para o desenho da solução global foram discutidos a partir das características necessárias e possuíram como categorias de análise os movimentos e posturas do trabalhador e a produtividade do sistema.

Na concepção e avaliação do subsistema mesa, a principal contribuição da modelagem e simulação humana digital foi a concepção de uma geometria capaz de acomodar os diferentes percentis ( 5 e 95) garantindo o espaço necessário à execução da atividade. Para esse subsistema, a principal restrição existente foi o pequeno espaço delimitado para o módulo de abastecimento de agulhas. Buscando melhorar a situação de trabalho em conformidade com os fatores de risco estabelecidos pelo instrumento EJA, foi projetada uma região de apoio aos antebraços do operador. Durante a etapa de simulação digital, também foi definida a necessidade de bordas arredondadas ao longo da superfície da mesa, não só devido aos aspectos do bem-estar humano, como citado no exemplo anterior, mas também para facilitar o manuseio das agulhas.

A definição da altura e de toda a estrutura da mesa também foi desenvolvida em ambiente digital. Buscou-se determinar uma altura adequada aos extremos populacionais que fosse compatível com o adequado funcionamento do conjunto, principalmente para evitar colisões com o subsistema canal e esteira. Tal subsistema definiu um limite mínimo de altura ao apresentar risco de colisão com os membros inferiores do manequim percentil 95 (análise ilustrada na Figura 8b) e, ao mesmo tempo, impôs um limite máximo devido à necessidade de alcance do percentil 5 .

$\mathrm{Na}$ concepção do subsistema canal e esteira, muitos conceitos puderam ser testados durante a etapa de simulação, com destaque para a contribuição sobre o posicionamento do canal. Em um primeiro momento, o canal foi projetado paralelo ao plano longitudinal do operador (conforme visualizado anteriormente na Figura 7b), porém, após a avaliação em ambiente digital e com a aplicação do EJA, observou-se a necessidade de sua inclinação em
a) Subsistema mesa
b) Subsistema canal e esteira
c) Subsistema pinça e pente
d) Subsistema carro de movimentação
e) Subsistema suporte para os pentes
f) Subsistema descarte de agulhas.

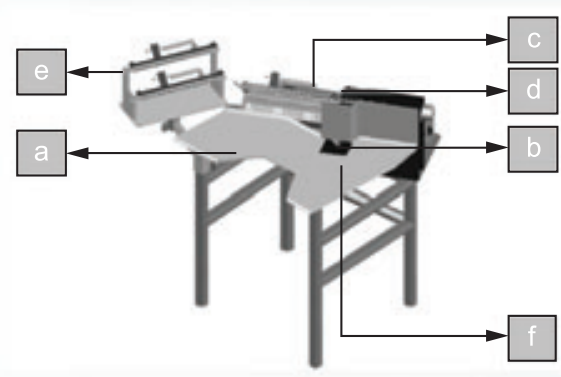

Figura 6. Ilustração com subsistemas definidos como recortes.

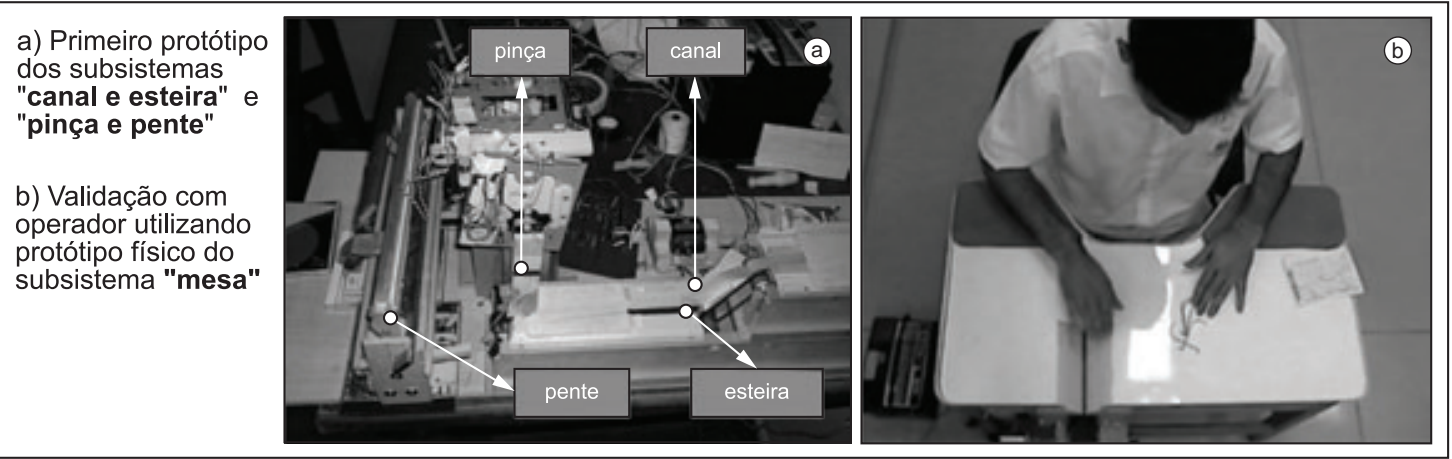

Figura 7. Prototipagem física de subsistemas fundamentais. 

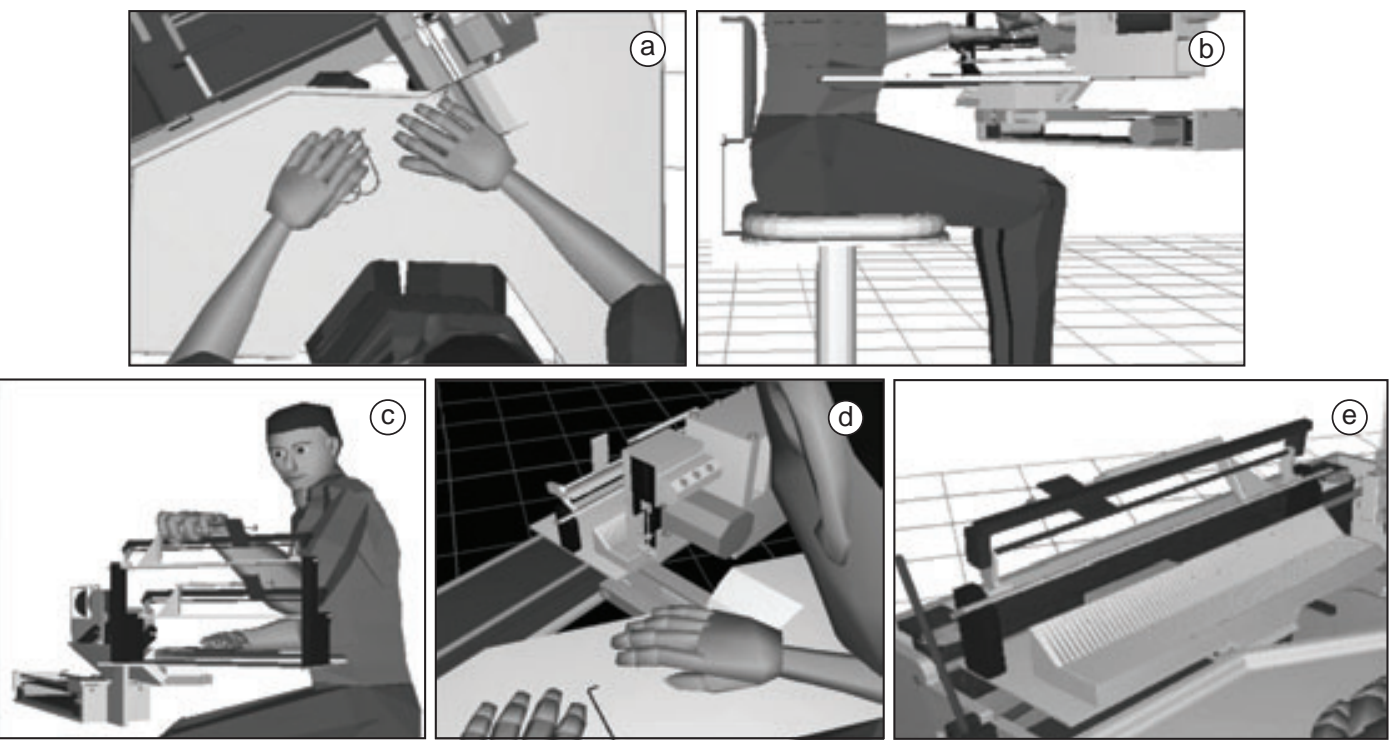

Figura 8. Simulações realizadas para desenvolvimento de proposta projetual.

30 graus no sentido anti-horário com referência ao plano citado, como mostra a Figura 8a. Tal alteração reduziu a amplitude do movimento e o risco associado às lesões repetitivas. Esta mudança resultou em um grande conjunto de alterações no modelo conceitual, contribuindo positivamente para o projeto do sistema global e diminuindo o grau de incerteza sobre sua eficiência. Com relação à esteira, a simulação permitiu identificar a necessidade de uma redução dimensional, devido, principalmente, à falta de espaço disponível.

$\mathrm{Na}$ etapa de simulação do subsistema pinça e pente, foi possível avaliar aspectos de segurança, definindo o posicionamento da pinça em uma região que oferecesse os menores riscos ao operador sem comprometer o sistema produtivo (Figura 8d).

No desenvolvimento do subsistema carro de movimentação, significativas contribuições foram decorrentes da aplicação das técnicas de modelagem e simulação humana digital, sendo, a principal delas, a concepção do sistema giratório acoplado à base do carro de movimentação. A princípio, o carro projetado possuía um sistema fixo e a posição final do pente estava fora da zona de alcance determinada pelos requisitos do projeto, e isso só pôde ser observado pela simulação com o percentil 5. Porém, com as alterações que foram agregadas ao longo do projeto e a necessidade de atender às exigências do EJA, o projeto foi alterado com a adição de um sistema giratório que permitiu a aproximação do pente ao operador e um melhor posicionamento da pega. Tais modificações viabilizaram o alcance de toda a população determinada e considerável diminuição de movimentos de flexão de coluna e de punho, impactando positivamente na avaliação realizada com o EJA.
Na concepção do subsistema suporte para os pentes, a simulação humana contribuiu diretamente para estabelecer características do suporte e dos sistemas de ajustes necessários visando o alcance dos operadores, conforme ilustrado na Figura 8c. A possibilidade de ajuste contribui diretamente para o aumento do espaço de regulação de modo a permitir as variabilidades individuais, inclusive para o modo operatório.

A concepção do subsistema descarte de agulhas foi resultado de desenvolvimentos ocorridos durante as etapas de simulação. A necessidade desse subsistema surgiu devido aos rigorosos sistemas de segurança, marcados principalmente pela existência de um grande número de dispositivos sensoriais óticos. Dessa forma, quando ocorresse uma falha no sistema de pinça ou do canal (por exemplo, a inserção de duas agulhas ao mesmo tempo) seria necessária a intervenção do operador. Com a concepção desse subsistema, as agulhas que fossem detectadas pelos sensores como fora do padrão eram automaticamente descartadas. O subsistema foi projetado no momento em que quase todos os elementos já estavam em fase avançada de concepção, o que acarretou uma dificuldade adicional na alocação física desse sistema global. A simulação humana digital contribui de forma significativa na compreensão da complexa restrição espacial existente no local por meio da análise detalhada dos equipamentos e as possibilidades de choque físico com os membros inferiores do manequim percentil 95 .

A partir da prototipagem digital, foi possível construir as especificações técnicas do novo posto de trabalho, consorciando diversos fatores e equacionando questões do bem-estar humano e produtividade. 
Quadro 1. Principais contribuições obtidas no desenvolvimento do balcão de atendimento.

\begin{tabular}{|c|c|}
\hline Categoria de análise & Contribuições da aplicação da simulação humana \\
\hline $\begin{array}{l}\text { Forma da superfície de } \\
\text { trabalho }\end{array}$ & $\begin{array}{l}\text { A simulação permitiu testar uma gama de formas do balcão, simulando } \\
\text { individualmente o guichê e diferentes arranjos com vários guichês. } \\
\text { Os testes virtuais permitiram definir as dimensões e a forma para comportar os } \\
\text { equipamentos e acessórios existentes no posto, bem como fatores de alcance e } \\
\text { alternância entre usuários destros e sinistros. }\end{array}$ \\
\hline Altura do tampo do balcão & $\begin{array}{l}\text { As simulações realizadas definiram a altura do tampo para a construção do } \\
\text { protótipo físico. Foram testadas, principalmente, a alternância postural em pé e } \\
\text { sentada e as diferenças antropométricas da população. }\end{array}$ \\
\hline $\begin{array}{l}\text { Apoio para os membros } \\
\text { superiores }\end{array}$ & $\begin{array}{l}\text { As simulações anteciparam a atividade futura possível, avaliando os espaços livres } \\
\text { para apoio de braços, punhos e mãos sobre a superfície de trabalho. }\end{array}$ \\
\hline $\begin{array}{l}\text { Apoio para os membros } \\
\text { inferiores }\end{array}$ & $\begin{array}{l}\text { As simulações possibilitaram verificar a posição das pernas e o giro livre da } \\
\text { cadeira sob a superfície de trabalho a ser prototipada fisicamente. } \\
\text { Foram utilizados nas simulações diferentes manequins, sendo possível estabelecer } \\
\text { a faixa de altura que o tablado regulável para apoio dos pés deveria ter para } \\
\text { execução da prototipagem física. }\end{array}$ \\
\hline Móveis auxiliares & $\begin{array}{l}\text { A modelagem virtual possibilitou o teste de diferentes formas e dimensões para os } \\
\text { móveis auxiliares, simulando a movimentação de entrada e saída de materiais. }\end{array}$ \\
\hline $\begin{array}{l}\text { Fluxo e movimento de } \\
\text { materiais }\end{array}$ & $\begin{array}{l}\text { As simulações permitiram avaliar diferentes desenhos para a entrada e saída de } \\
\text { materiais, testando os prós e contras da adoção de cada lógica. }\end{array}$ \\
\hline $\begin{array}{l}\text { Interação entre atendente e } \\
\text { cliente }\end{array}$ & $\begin{array}{l}\text { Por meio das simulações foi possível equacionar a distância necessária entre } \\
\text { atendentes e clientes, garantindo o maior espaço de trabalho possível para o } \\
\text { atendente e mantendo um alcance confortável para troca de objetos entre eles. }\end{array}$ \\
\hline Facilidade de comunicação & $\begin{array}{l}\text { A simulação com o arranjo de vários balcões em uma unidade de atendimento } \\
\text { permitiu avaliar possíveis relacionamentos entre atendentes. Esses testes } \\
\text { determinaram o tamanho e a forma do anteparo entre guichês. }\end{array}$ \\
\hline $\begin{array}{l}\text { Segurança de produtos, } \\
\text { numerário e segurança } \\
\text { pessoal }\end{array}$ & $\begin{array}{l}\text { Os testes virtuais para essa categoria proporcionaram, principalmente, determinar } \\
\text { as vantagens da gaveta com abertura tipo "tampa" via sistema informatizado. }\end{array}$ \\
\hline
\end{tabular}

Quadro 2. Principais contribuições obtidas durante a concepção do posto de manufatura.

\begin{tabular}{|l|l|}
\hline Categoria de análise & \multicolumn{1}{c|}{ Contribuições da aplicação da simulação humana } \\
\hline Canal de alimentação & $\begin{array}{l}\text { A simulação permitiu definir uma angulação do canal com relação ao trabalhador } \\
\text { que eliminou a necessidade de movimentos de flexão do punho para cada agulha, } \\
\text { impactando consideravelmente a análise pelo instrumento EJA. }\end{array}$ \\
\hline Geometria da mesa & $\begin{array}{l}\text { Utilizando manequins com percentis 5 e 95, foi possível conceber uma mesa que } \\
\text { atendesse a mais de 90\% da população sob estudo, considerando todos os dispositivos } \\
\text { previstos. O estudo concentrou-se nas características dimensionais da mesa, forma } \\
\text { geométrica principalmente do recorte existente para aproximação do operador e o risco } \\
\text { de colisão entre os membros inferiores do operador e a esteira que se situa sob a mesa. }\end{array}$ \\
\hline Suporte para pentes & $\begin{array}{l}\text { A simulação humana foi determinante como ferramenta projetual do suporte para os } \\
\text { pentes. Dimensões, geometria, encaixe, localização e, principalmente, os sistemas } \\
\text { desejáveis de ajuste foram projetados com base nas avaliações e antecipações possíveis } \\
\text { com o software. }\end{array}$ \\
\hline $\begin{array}{l}\text { Esteira de transporte } \\
\text { de agulhas }\end{array}$ & $\begin{array}{l}\text { Por meio de simulações com um manequim masculino percentil 95, foi possível } \\
\text { projetar a esteira de transporte de agulhas com características geométricas e } \\
\text { posicionamento com relação aos membros inferiores do operador de forma que não } \\
\text { houvesse a possibilidade de colisão. }\end{array}$ \\
\hline $\begin{array}{l}\text { Conjunto estrutural } \\
\text { da mesa }\end{array}$ & $\begin{array}{l}\text { Com o apoio da modelagem digital e simulações humanas, os travamentos de } \\
\text { sustentação da mesa foram posicionados de forma que o operador não utilizasse tal } \\
\text { estrutura como apoio para os pés ou pernas. Devido a sua forma geométrica não } \\
\text { possibilitar um apoio estável e planar, seu uso poderia ocasionar danos à saúde do } \\
\text { operador devido ao aumento da pressão pela força exercida em uma pequena área do } \\
\text { corpo humano. }\end{array}$ \\
\hline
\end{tabular}




\section{Resultados}

Os resultados da utilização da simulação são compatíveis com os benefícios destacados ao longo deste trabalho: diminuição do tempo de desenvolvimento, auxílio na comunicação e, principalmente, a consideração de fatores ergonômicos de forma antecipada.

Especificamente, para cada estudo podem-se citar alguns pontos que denotam os resultados obtidos. Para o primeiro caso, a utilização da prototipagem virtual atuou como facilitadora da comunicação entre os profissionais envolvidos no projeto (grupo de trabalho formado por trabalhadores da empresa e por pesquisadores). A antecipação dos campos visuais do atendente e do cliente foi de grande auxílio na atividade projetual, e, por fim, diversos acertos da ordem de poucos centímetros foram realizados no ambiente virtual, ganhando tempo e antecipando reconsiderações ergonômicas do pós-uso. No Quadro 1, estão sintetizadas as principais contribuições da simulação humana nesse caso específico.

Para o segundo caso, pode ser destacada a utilização da simulação como meio de comunicação entre os projetistas e os engenheiros da empresa contratante, visando à validação das soluções propostas em consonância com a política da empresa e as tecnologias disponíveis. Outro destaque bastante específico desse estudo foi o uso do software como ferramenta de projeto, equacionando diversas restrições e conflitos das características geométricas do posto de trabalho. O Quadro 2 apresenta algumas das principais contribuições.

\section{Conclusões}

Pôde-se verificar a versatilidade para a aplicação da modelagem e simulação humana e os benefícios advindos desta tecnologia em dois estudos de caso.

Uma primeira distinção existente entre eles foi a ordem cronológica dos acontecimentos da prototipagem física e da prototipagem digital durante o processo de projeto. Para o balcão de atendimento, a prototipagem física ocorreu após as etapas de modelagem e simulação. No posto de manufatura, a prototipagem física se antecipou à simulação e não ocorreu nas etapas finais do processo. Primeiramente, essa constatação confirma a visão dos autores desse estudo de que os processos de projeto não são lineares e nem seguem padrões definidos, apresentando especificidades e alto grau de variabilidade. Nesse trabalho, a validação conceitual para o segundo estudo de caso das propostas iniciais por meio da prototipagem física de alguns dos subsistemas, pode ser considerada a principal razão dessa diferenciação.

Outro diferencial explícito entre os casos apresentados foi a interação entre o ato de projetar e as análises a partir das simulações. No desenvolvimento do posto de manufatura (caso 2), as modificações no projeto resultantes das simulações foram frequentes e conduziram o processo de projeto durante a etapa de detalhamento do conceito global. No entanto, apesar das influências da simulação humana no projeto conceitual do balcão de atendimento (caso 1), esta atuou com maior ênfase validando e intermediando o processo social existente do que uma ferramenta técnica de desenvolvimento de projeto.

Os casos de aplicação apresentados mostram que cada vez mais essa tecnologia poderá ser adotada por empresas de diferentes setores que objetivam novas vantagens competitivas, melhorando condições de trabalho e contribuindo para a eficácia produtiva.

Porém, questões como usuários bem treinados, necessidade de know-how nas áreas de projeto, ergonomia, biomecânica e computação, além da capacidade de análise e síntese dos resultados gerados, são requisitos necessários, e, portanto, desafios para a utilização desta tecnologia. Outra questão que deve sempre ser considerada neste tipo de simulação é que os "trabalhadores digitais fazem somente o que nós pedimos para eles fazerem”, isto é, a simulação é altamente dependente da visão do trabalho que o usuário dessa tecnologia possui ou, que tem a sua disposição, fazendo com que a subjetividade encontrada no trabalho real possa não ser encontrada na simulação, ou até mesmo apresentar diferenças significativas entre $o$ trabalho real executado e o trabalho simulado, devido a sua percepção deficiente, podendo comprometer a real eficiência de todo o processo.

Os resultados apresentados mostram que, a utilização dessa tecnologia de forma estruturada e baseada conceitualmente, pode ser considerada um instrumento auxiliar na busca pela consideração da futura atividade possível e identificação de possíveis constrangimentos em projetos de situações produtivas. No entanto, torna-se necessária a compreensão de que tal ferramenta é própria da ergonomia clássica anglo-saxônica, de caráter altamente tecnicista, com ênfase em fatores biomecânicos, antropométricos e com grande foco nas análises quantitativas.

Isto posto, conclui-se que o desafio está no uso de tais aplicações de forma a incorporar a atividade presente no cotidiano do trabalho das situações de referência, contribuindo para que cenários evolutivos possam ser desenvolvidos, discutidos e validados com o auxílio deste objeto intermediário entre os diversos agentes dos processos de projeto de postos de trabalho.

\section{Referências}

BÉGUIN, P.; WELL-FASSINA, A. Das simulações das situações de trabalho à situação da simulação. In: DUARTE, F. (Org.). Ergonomia e projeto: na indústria de processo contínuo. Rio de Janeiro: Editora COPPE/ UFRJ; Lucerna, 2002. p. 75-83. 
BERTONCELLO, D. et al. Utilização de instrumento para caracterização de fatores de risco: resultados de uma aplicação em larga escala em linhas de produção. In: CONGRESSO BRASILEIRO DE ERGONOMIA, 13., 2004, Fortaleza, Brasil. Anais... Fortaleza: ABERGO, 2004.

BRAATZ, D. et al. Aplicação de Dados Antropométricos Bidimensionais na Construção de Manequins Humanos Tridimensionais. In: CONGRESSO BRASILEIRO DE ERGONOMIA, 12., 2002, Recife, Brasil. Anais... Recife: ABERGO, 2002.

BRASIL. Ministério do Trabalho. Portaria MTPS/ GM no 3751, de 23 de novembro de 1990. Ltr.5412/1474-NR17- Ergonomia. Diário Oficial da República Federativa do Brasil, Brasília, DF, nov. 1990.

BUCCIARELLI, L.L. Designing Engineers. Cambridge: MIT Press, 1994.

DANIELLOU, F. A análise da atividade futura e a concepção de instalações externas. In: DUARTE, F. (Org.). Ergonomia e projeto na indústria de processo contínuo. Rio de Janeiro, 2002a. p. 75-83

DANIELLOU, F. Métodos em ergonomia de concepção. In: DUARTE, F. (Org.). Ergonomia e projeto: na indústria de processo contínuo. Rio de Janeiro: Ed. COPPE/UFRJ; Lucerna, 2002b. p. 29-33.

DANIELLOU, F. A análise do trabalho: critérios de saúde, critérios de eficácia econômica in CASTILLO, J. J.; LÓPEZ, J. V. (Org.). Ergonomia: Conceitos e Métodos. Lisboa: Dinalivro, 2005.

DANIELLOU, F. Lérgonomie et les acteurs de la conception. Confeences Thematiques. Ergonomie et ingenierie. 1995. p. 27-32.
FEYEN, R. et al. Computer-aided ergonomics: a case study of incorporating ergonomics analyses into workplace design. Applied Ergonomics, v. 31, p. 291-300, 2000. http://dx.doi.org/10.1016/S0003-6870(99)00053-8

FONTES, A. R. M. et al. Projeto de Guichê de Atendimento Contextualizado pela Análise Ergonômica do Trabalho. GEPROS - Gestão da Produção, Operações e Sistemas, v. 2, p. 111-124, 2006. http://dx.doi.org/10.1016/ S0143-8166(97)00006-7

JONES, P. R. M. Three-dimensional surface anthropometry: applications to the human body. Optics and Lasers in Engineering, v. 28, p. 89-117, 1997.

MENEGON, N. L. et al. Pesquisa Antropométrica Embraer. In: CONGRESSO BRASILEIRO DE ERGONOMIA, 12., 2002, Recife, Brasil. Anais... Recife: ABERGO, 2002.

MENEGON, N. L. Projeto de processos de trabalho: o caso da atividade do carteiro. 2003. 259 f. Tese (Doutorado em Engenharia de Produção)-Universidade Federal do Rio de Janeiro, Rio de Janeiro, 2003.

MONTMOLLIN, M. Ergonomias. In: CASTILLO, J. J.; VILLENA J. (Org.). Ergonomia: conceitos e métodos. Lisboa: Dinalivro, 2005. p. 103-111.

SIZEGERMANY. Press information. Disponível em: <http://www.hohenstein.de/ximages/1399929_ sgabschlus.pdf $>$. Acesso em: 11out. 2010.

ZIOLEK, S. A.; KRUITHOF, P. C. J. Human Modeling \& Simulation: A primer for practitioners. In: HFES, 44, 2000, San Diego, USA. Proceedings... San Diego: HFES, 2000. 